\title{
ENSINO A DISTÂNCIA: EXPERIÊNCIAS E INOVAÇÕES
}

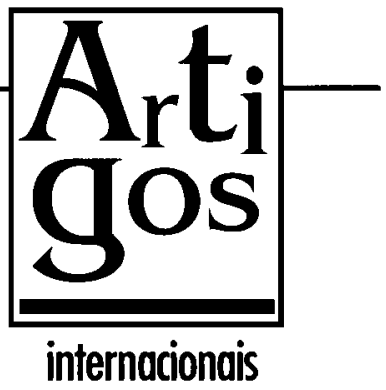

Neste número publicamos, com exclusividade, a primeira parte do artigo Transmissão Educativa, da revista Tendências da Pesquisa de Comunicação, do Centro para o Estudo da Comunicação e Cultura, da Universidade St. Louis, EUA. Os autores tratam do uso do rádio e da TV para a transmissão de programas educativos. Citam as experiências latino-americanas, destacam o crescente uso destes recursos na China e demais países asiáticos e discutem a eficácia de tais programas para elevar o nível de conhecimento de seus usuários.

Pioneiros das novas tecnologias de comunicação - tais como Edison e Marconi - esperavam que um dos principais usos de suas invenções fosse trazer educação para as massas. Lord Reith, da BBC (British Broadcasting Corporation), fundador do conceito de transmissão como serviço público, enfatizou a educação no seu famoso trílogo, que resume os objetivos da BBC: "educar, informar e entreter". Os maiores mercados e retornos de investimento de capital se encontravam, entretanto, na transmissão de entretenimento e as emissoras comerciais se moveram diretamente para aquela direção. Hoje, a transmissão preferida pelo público, sem dúvida, é a de entretenimento.

\section{OS AUTORES}

Robert A. White

Pradip Thomas

Editores
Nos últimos 20 anos, porém, o uso do rádio e da TV na educação voltou à evidência. O mais impressionante é que surgiu grande variedade de novos serviços educativos e combinaram-se, engenhosamente, velhas e novas tecnologias. Com o implemento da transmissão educativa, milhões de pessoas puderam ter acesso ao tipo de educação de que elas precisavam, no momento em que precisavam.

A instrução via meios de comunicação está se tornando menos uma enteada dos sistemas educacionais e cada vez mais sua vitrina. A televisão da Universidade Aberta Britânica, tratada com ceticismo quando lhe foi dado o Alvará Real em 1969, agora envolve, anualmente, uma média de 60 mil estudantes e concedeu quase 100 mil títulos universitários. O sucesso da Universidade Aberta encorajou adaptações em uns 20 países. A transmissão educativa é especialmente significante para países em desenvolvimento. A Federação Latino-Americana das 
Rádios Educativas registra que seus 50 ou mais sistemas filiados, os quais operam praticamente em todos os países do continente, têm mais de um milhão de estudantes do ensino básico num total de mais de 15 milhões de pessoas que se beneficiam da transmissão educativa na agricultura, saúde e organizações populares.

Ao mesmo tempo, o caminho para se chegar ao atual nível de aprimoramento na transmissão educativa foi percorrido com muitas tentativas dispendiosas e frustradas. Neste artigo chamamos a atenção dos leitores para a potencialidade do uso da transmissão educativa e, especialmente, as maneiras de torná-la uma experiência de aprendizado mais eficaz para os alunos.

\section{O USO CRESCENTE DAS TRANSMISSÕES NA EDUCAÇÃO}

Quando o rádio foi introduzido na década de 20 , muitas pessoas conceberam de modo exagerado o enorme poder da mídia de influenciar comportamentos. As primeiras tentativas de educação através da transmissão também provocaram expectativas maiores do que os resultados inicialmente alcançados. Sabemos, agora, muito mais sobre que tipo de educação pode ou não ser conseguido através do rádio, da TV ou de alguma combinação das novas tecnologias tais como o videotexto, TV a cabo, vídeo, transmissão via satélite e computadores.

Numa pesquisa recente feita para o Departamento de Pesquisas de Programação e Audiência da Rádio Sueca, resumida no boletim daquele departamento (Findahl, 1989), caíram por terra as persistentes suspeitas de que "a televisão não pode ensinar". Pois verificou-se o sucesso das Uni- versidades Abertas e os bons resultados de estudos e pesquisas alcançados em todo o mundo. Sabemos, por exemplo, que a televisão é extremamente poderosa no que tange à Agenda Setting ${ }^{1}$, ̀̀ qual devotamos muito da nossa atenção. Ela pode não nos dizer o que pensar, mas tem muita influência sobre o que nós pensamos. Seu poder de comunicar fatos simples e imagens visuais é comprovado pelas vendas contínuas de tempo para comerciais na programação.

Embora os já bem informados apreendam mais informação da televisão do que os menos informados, a televisão atinge grupos na sociedade que outros meios informativos não alcançam. A TV comunica mais facilmente a informação concreta. E está provado que os programas apropriadamente estruturados colaboram muito para estimular o pensamento e o discernimento. Um fator chave nesse efeito é o modo que o material transmitido se relaciona com o que o espectador já sabe. Entretanto, como na maioria das televisões prioriza-se a programação comercial, o espectador pode se acostumar com programas que nada exigem intelectualmente, o que pode levá-lo a considerar a TV como meio exclusivo de entretenimento e relaxamento. A estrutura comercial também tende a frisar conteúdos que chamam a atenção em detrimento dos que explicam e aprofundam.

Programas educativos tendem a ser marginalizados, relegados aos horários menos nobres, segundo os padrões comerciais. Findahl conclui que a televisão pode ensinar, mas sua habilidade para fazêlo depende dos objetivos e dos métodos de que dispõem (1989, p.4).

Praticamente a mesma conclusão pode se aplicar ao rádio.

1. É uma hipótese em pesquisa de comunicação que estuda a influência dos meios de comunicação de massa sobre seus receptores a partir dos efeitos cumulatórios determinados pela pauta dos assuntos veiculados. Ou seja, tal hipótese defende que os assuntos discutidos nas conversas dos receptores são incutidos pela agenda da mídia. Ler sobre o assunto: WOLF, Mauro. Teorias da comunicação. 2.ed., Lisboa: Presença, 1992, p.123-156. (N.E.) 
Os primeiros livros sobre mídia educativa $^{2}$ foram úteis no mapeamento dos principais padrões e na distinção das categorias de uso das mídias. Essas categorias visam a:

a) suplementar a educação da escola convencional;

b) estender as oportunidades da educação formal para além da sala de aula;

c) transmitir uma educação não-formal.

\section{Os objetivos da transmissão educativa}

Comparando o livro de Jamison e McAnany ${ }^{3}$ de 1978 com os de Bates em 1984 e Holmberg em $1986^{4}$, detectamos um consenso crescente relacionado com três objetivos básicos ou justificativas para a instrução via meios de comunicação.

O primeiro é melhorar a qualidade de instrução fornecendo informações ou experiências que os professores ou livros comuns não podem dar.

A instrução a distância pode também in-
troduzir linguagens da mídia audiovisual
rica em aspectos ainda não utilizados pe-
lo ensino convencional, como Gavriel Sa-
loman sugeriu (1979).

O ensino de uma língua estrangeira, por exemplo, melhorou a partir das aulas transmitidas de uma central, mesmo recorrendo a um menor número de professores.

$O$ segundo defende que a instrução a distância melhora o acesso de pessoas que moram em áreas isoladas ou que, devido a seus compromissos, não podem ir à escola. Este acesso pode ser conseguido tanto "estendendo" os níveis existentes (por exemplo, somando níveis escolares à instrução pela
TV) quanto substituindo as escolas convencionais pelo ensino a distância para indivíduos ou pequenos grupos organizados.

Terceiro, a transmissão pode reduzir o custo, obtendo um certo nível de aprendizado, sem multiplicar a estrutura convencional e oferecendo um time central especializado no ensino dirigido a milhares de estudantes. Nas nações mais pobres, com o rápido crescimento das necessidades educacionais, a transmissão educativa tem sido praticamente a única maneira de tornar a educação acessível a grandes parcelas da população.

Estas vantagens, obviamente, dependem muito do contexto, tipo e objetivos de educação para a qual a transmissão é usada. Antes de olhar pesquisas mais detalhadas descrevendo e avaliando os diferentes usos da transmissão na educação, é útil destacar as principais classificações de experiências educacionais através dos meios de comunicação, identificadas por Bates, Jamison, McAnany e outros.

\section{A transmissão na educação formal}

Esta categoria abrange a transmissão educativa como parte de uma série organizada de cursos que visam a uma graduação oficialmente reconhecida e enfatizam o conhecimento profissional ou geral ao invés de práticas ocupacionais. Dois tipos de transmissão de educação formal podem ser claramente evidenciadas. A primeira é a transmissão dirigida ao professor, como parte do material didático das escolas primárias, secundárias e universidades convencionais. As transmissões nas escolas deste tipo servem para enriquecer ou suplementar os conteúdos existentes, os

2. Tais como Big media, little media (Grande mídia, pequena mídia) de Wilbur Schramm (1977). (N.E.)

3. BATES, Anthony. Broadcasting in education: an avaluation. London: Constable and Co., 1984. (Transmissão na educação: uma avaliação)

4. JAMISON, Dean T., McANANY, Emile. Radio for education and development. Beverly Hills, CA: Sage Publications Inc., 1978. (Rádio para educação e desenvolvimento)

HOLMBERG, Börge. Growth and struture of distance education. London: Croom Helm, 1986. (Crescimento e estrutura da educação a distância) 
quais devem ser adaptados à rotina das escolas e às necessidades dos professores que as utilizam.

Um segundo tipo de transmissão de educação formal é para programas de graduação fora das salas de aula convencionais. Ele geralmente usa a transmissão educativa de acordo com a flexibilidade dos horários, situações cotidianas e necessidades dos alunos.

Desde o século XIX, muitas universidades têm tido cursos de correspondência para alunos que não podem frequientar as aulas normais. $O$ novo, especialmente desde a década de 50, são as instituições de ensino primário, secundário e superior a distância, oferecendo diplomas próprios reconhecidos e usando rádio, TV e outros meios como veículos de ensino.

As escolas de rádio na América Latina e as Universidades Abertas moldadas na Universidade Aberta Britânica constituem-se exemplos dessa prática.

\section{A transmissão na educação não-formal}

A transmissão para a educação nãoformal visa às pessoas que não querem, necessariamente, uma graduação, mas que podem usar as informações fornecidas pela programação para objetivos específicos. A transmissão de educação básica de adultos não pressupõe nenhuma preparação educacional anterior. É uma forma abrangente de transmissão educativa porque pode ser o único acesso que muitos têm para tal educação. Sua aplicação mais comum é desenvolver a capacidade de ler e escrever e a habilidade numérica, especialmente em países em desenvolvimento onde não há escolas primárias adequadas ou onde muitas crianças deixam de estudar cedo para trabalhar no campo. Pode, também, incluir educação familiar ou dirigida aos pais, educação de consumo e econo- mia doméstica, ensinando as dicas necessárias para tornar acessíveis os serviços sociais e de saúde existentes, ou pode ser usado para ajudar pessoas a encarar mudanças no emprego ou carreiras, como Anthony Kaye sugere.

A educação contínua é dirigida às pessoas que já passaram pelas escolas de graduação e estão interessadas em complementar ou atualizar seus conhecimentos.

$A$ instrução anterior à entrada no sistema educacional formal geralmente visa reduzir as diferenças educacionais devidas à pobreza, problemas familiares ou subdesenvolvimento regional. A Oficina de TV da Criança em Nova York, que concebeu o Vila Sésamo e outros programas de entretenimento educativo para crianças na pré-escola, é uma instituição especificamente estabelecida para esse propósito. Também os departamentos dedicados ao público infantil de praticamente todas as emissoras nacionais criam programas educativos dessa natureza.

\section{A transmissão para o desenvolvimento}

Esta categoria é distinta da educação não-formal porque a instrução é direcionada não apenas para o desenvolvimento das habilidades individuais mas também para ajudar indivíduos e grupos, contribuindo com os objetivos sócio-econômicos nacionais, com a melhoria das comunidades ou com os objetivos de movimentos sócio-políticos. Este tipo de educação freqüentemente inclui uma forte dimensão motivacional e uma consciência social emergente. Bates e outros distinguem três tipos dentro desta categoria. O primeiro é uma instrução básica com orientação voltada às habilidades na agricultura, saúde, participação cívica, planejamento e gerência familiares, gerência dos empreendimentos econômicos domésticos, compreensão dos sistemas econômicos e políticos modernos, etc. Todos eles são geralmente orientados no sentido de melhorar 
a qualidade de vida e ajudar grupos específicos, tais como camponeses ou imigrantes urbanos de baixa renda, a participarem do desenvolvimento nacional.

Um segundo é a transmissão livre, que usa freqüentemente métodos de "campanha", para obter do público alvo compreensão, precaução e motivação, em geral com relação a um problema comunitário específico. O objetivo, pelo menos em "campanhas", é conseguir uma rápida implementação de novos padrões de comportamento relacionados, por exemplo, com a prevenção de contágio em surtos de epidemias. As campanhas usam vários meios para garantir uma difusão total de informações urgentes, como os esforços da Organização Mundial de Saúde e outros para espalhar informações precisas sobre a AIDS.

Finalmente, a transmissão educativa para mudanças sociais e ações políticas, que inclui procedimentos específicos para criar uma consciência contrária à violação dos direitos humanos, para desenvolver apoios a uma nova legislação ou para criar auto-estima em grupos de baixa renda. Por exemplo, algumas estações de rádio educacionais na América Latina adaptaram os métodos de conscientização de Paulo Freire para o rádio. Elas integraram conscientização com instrução, utilizando-se da premissa de que os problemas só serão solucionados se houver mudanças fundamentais na estrutura de poder.

\section{A EFICÁCIA \\ DA TRANSMISSÃO A DISTÂNCIA NA EDUCAÇÃO FORMAL}

Nos últimos dez anos pode-se perceber uma expansão sem precedentes da educação a distância. São mais de dois milhões e meio de estudantes apenas na Universidade Central de Rádio e Televisão da China; no mundo inteiro são cerca de dez milhões. Como aponta Dean Nielson, na Development Communication Report - DCR ${ }^{5}$, tal crescimento massivo do acesso ao ensino superior - particularmente na Ásia, onde tais instituições, similares à chinesa, existem no Paquistão, Índia, Indonésia, Coréia, Turquia, Sri Lanka, Tailândia, Malásia e Japão - está mudando radicalmente o padrão de ensino superior em muitas partes do mundo.

Na Ásia o estudante da Universidade Aberta é geralmente uma pessoa que aproveita a chance de obter um diploma universitário na esperança de conseguir um emprego melhor.

Frequientemente as mesmas instituições colaboram com empresas ou profissionais, oferecendo cursos de treinamento nãoprofissionalizantes a fim de aperfeiçoar as habilidades dos empregados, profissionais ou oficiais do governo.

João Oliveira, na mesma edição (p.12), lista algumas razões pelas quais o ensino a distância está se tornando tão popular. Ele pode ampliar as oportunidades educacionais em países onde os recursos são escassos; oferece respostas flexíveis numa época em que as pessoas estão exigindo uma diversidade de tipos de educação e treinamento, que não podem ser encontradas nas escolas tradicionais; oferece meios de se atualizar rapidamente o conhecimento técnico, justamente quando ocorre a informatização dos bancos, linhas aéreas e outras atividades do dia-a-dia, mesmo em países que mal foram tocados pela "modernização". Ao mesmo tempo, o equipamento e a infra-estrutura para este tipo de educação estão se tornando mais baratos, mais confiáveis e mais disponíveis de modo geral, assim como mais acessíveis ao usuário.

\footnotetext{
5. Development Communication Report, 1988/4 (n.63). Washington, DC: Clearinghouse on Development Communication. (edição especial de educação a distância como suplemento da "Interative radio: education in the classroom" - "Rádio Interativo: educação na sala de aula”).
} 
O processo de desenvolvimento em países subdesenvolvidos tem se tornado cada vez mais complexo a ponto de, se o país desejar desenvolver certos tipos de sistemas tecnológicos, terá que engajar-se num programa educacional massivo, para que as pessoas possam operá-los. Finalmente, o sucesso das instituições como a Universidade Aberta na Inglaterra e a Universidade Nacional de Tecnologia nos Estados Unidos rendeu uma maior credibilidade à eficácia educacional das instituições de ensino a distância.

Mas os primeiros programas de ensino a distância ganharam uma reputação muito ruim, que ainda permanece - mesmo que desmerecidamente - embora suas formas contemporâneas sejam melhor concebidas, melhor consolidadas e melhor organizadas. Os críticos, muitos deles funcionários das escolas e professores, ainda tendem a enfatizar os defeitos do ensino a distância, enquanto ignoram muitos dos defeitos do ensino tradicional que esse poderia ajudar a corrigir. John K. Mayo, na sua pesquisa para a edição especial do DCR (p.16), pesa alguns prós e contras do ensino a distância e conclui que não há ainda pesquisas suficientes para responder muitas das principais questões sobre o assunto com algum grau de certeza. Mas a promessa oferecida de resolver as necessidades modernas, especialmente em países em desenvolvimento, faz do esforço, necessário para entendê-lo e usá-lo efetivamente bem, valer a pena.

\section{Usos da instrução a distância nas escolas}

A maioria dos países que tem um serviço público de transmissão educativa ou uma forte regulamentação sobre serviços públicos nos veículos comerciais, já transmitiram para escolas no período normal de aulas. Por exemplo, Bates registra que no ano letivo de 1981-82 a BBC apresentou 76 séries diferentes de rádio e a $\mathbf{B B C}$ e o sistema comercial independente, juntos, tiveram um total de 98 séries de TV. Uma série é geralmente composta de uns dez programas interligados, de 30 minutos cada, com tópicos relacionados com o currículo escolar. No Canadá a transmissão educativa é restrita quanto ao alcance, como é o caso da TV Ontário, um dos sistemas maiores e mais antigos. Nos EUA, com um sistema predominantemente comercial, os programas escolares são transmitidos ou distribuídos a cabo e por microondas pelos sistemas educativos estaduais, através de consórcios entre os estados vizinhos; ou pelo corpo escolar de grandes áreas metropolitanas; ou ainda através de sistemas paroquiais escolares urbanos.

\section{Quase que universalmente, as transmis- sões escolares são usadas não para substi- tuir o professor em uma matéria mas pa- ra enriquecer uma atividade na qual o professor é indispensável.}

Nos últimos anos os programas de TV e rádio se tornaram uma "fonte de aprendizado" adicional, oferecendo materiais que não estariam disponíveis de outra maneira. Por exemplo, as câmeras de TV ou de cinema podem auxiliar os microscópios; a TV recria a história, dramatiza eventos correntes ou leva os estudantes a lugares desconhecidos. Com equipamentos de gravação de baixo custo mais amplamente disponíveis em escolas, é comum, agora, o professor preparar um curso antecipando cuidadosamente $o$ uso dos programas de radiodifusão como apoio. Quanto maior o planejamento e a habilidade em integrar o material ao currículo existente, maior a eficácia. Um problema universal muito destacado por Bates é que muitos programas de rádio $\mathrm{e} \mathrm{TV}$, excelentes, estão cobertos por leis de direitos autorais e só podem ser obtidos em fitas de vídeo por preços exorbitantes. A resolução do problema dos direitos autorais para o uso escolar abriria um amplo campo para a veiculação destes materiais. 


\section{O suplemento acompanhando o} DCR $n^{\circ} 63$ discute vários programas experimentais de rádio interativo, que é uma das formas de instrução veiculada em escolas, na América Latina e em outros lugares. As séries de projetos apoiados pelo USAID (United States Agency for Internacional Development - Agência Internacional de Desenvolvimento dos Estados Unidos) começaram com o ensino de matemática do primeiro grau na Nicarágua, durante o período de 1973 a 1979. Projetos em outros países, baseados nos padrões desenvolvidos na Nicarágua, ensinavam não apenas matemática mas também leitura, escrita, ciências naturais e ciências sociais a estudantes da primeira à quarta séries do primeiro grau. $\mathrm{O}$ novo projeto-piloto hondurenho para o ensino de matemática se mostrou tão popular que $70 \%$ dos professores da área coberta pelas transmissões a distância quiseram adquirir pacotes com os programas durante os primeiros oito meses do projeto, em 1985. Apesar de os professores e as escolas terem que pagar parte do custo, os programas foram mais amplamente aceitos nas áreas rurais mais pobres do que nas escolas urbanas. Um projeto de pesquisa no Nepal, usando métodos similares para o treinamento de professores de nível superior, vem sendo feito desde 1978.

A instrução a distância é particularmente útil no ensino de áreas específicas do conhecimento, tais como as ciências que têm avanços tecnológicos mais acentuados. É também útil na discussão de temas sociais complexos, tal como a discriminação racial, que podem colocar um professor numa situação emocionalmente instável, ou que exija habilidades que o professor comum pode não ter, como falar outra língua. O material veiculado pode ser especialmente útil na resposta aos interesses particulares de uma classe, os quais o currículo ou textos não prevêem.

\section{As transmissões na escola} são usadas com eficácia?

Bates nota que, surpreendentemente, nem as escolas nem as transmissoras, na maioria dos países, fizeram avaliações muito boas ou atualizadas. Uma pesquisa de 1977 sobre transmissões em escolas da Europa, realizada pelo West German International Institute for Educational Broadcasting (Instituto Internacional de Transmissão Educativa da Alemanha Ocidental), revela que apenas 16 das 40 instituições citadas fizeram algum tipo de pesquisa de avaliação nos dez anos anteriores.

As estatísticas britânicas mais sistematicamente coletadas, entretanto, podem indicar uma tendência, pelo menos na Europa. No Reino Unido, no ano escolar de 1981-82, quase todas as escolas tinham receptores de rádio e TV e gravadores de áudio. À medida que o uso do rádio declinou consideravelmente, desde 1978, o uso da TV aumentou.

A porcentagem de escolas de segundo grau que usam pelo menos alguns programas de TV aumentou de $85 \%$ em 1978 para $92 \%$ em 1982. Mais significante, a média de séries de televisão educativas assistidas por ano aumentou de 8,6 para 13,3 por escola no mesmo período.

Os programas de TV mais usados são de história e eventos correntes, enquanto programas de língua estrangeira, surpreendentemente, estão entre os menos usados.

Na sua coleta de dados da experiência britânica e de outros estudos, Bates sugere que as condições mais importantes para a eficácia são:

a) provisão adequada de equipamentos de gravação;

b) maior esclarecimento ou sugestão aos professores de como tais materiais devam ser usados, especificamente para cada matéria; 
c) maior treinamento inicial e em serviço para os professores sobre o uso das transmissões;

d) tempo adequado (pelo menos dois períodos escolares subsequientes) para possibilitar o acúmulo, por completo, do impacto da série. Por exemplo, a rede japonesa NHK $^{6}$ descobriu que os estudantes em classes com transmissões, comparados com aqueles sem acesso a elas, começaram a mostrar melhorias significativas apenas com o uso contínuo e regular, durante o período de um ou dois anos, para que os professores e os alunos se tornassem familiarizados com este novo método de aprendizado.

\section{A pesquisa da Universidade de Stanford}

A pesquisa mais cuidadosa, detalhada, sistemática e cumulativa sobre a eficácia da educação a distância foi desenvolvida na Universidade de Stanford nos anos em que Wilbur Schramm dirigiu o Instituto de Pesquisas de Comunicação (1960-1975). A síntese mais compreensível que Bates pôde citar em 1984 é ainda Big Media, Little Media de Schramm, mas se apoiando firmemente em dados de estudos anteriores, referentes à década de 60 . O livro de Jamison e McAnany de 1978 resume muito da pesquisa de Stanford sobre o rádio na década de 70 .

Um dos projetos-piloto mais cuidadosamente desenhados usando as transmissões de rádio em escolas primárias foi o Projeto de Matemática no Rádio realizado na Nicarágua na década de 70 .

O projeto transmitia uma aula de 30 minutos pelo rádio seguidos de 30 minutos de atividades orientadas pelo professor. No seu terceiro ano operacional, um pouco antes de ser interrompido pelo governo nicaraguiense, as transmissões estavam alcan- çando muitos milhares de estudantes do primeiro grau. Cada estudante recebia uma folha de questões e para resolvê-las eles eram orientados pelas aulas transmitidas, nas quais eram previstos espaços de tempo para as respostas uníssonas dos estudantes, seguidos da resposta pela própria programação. A tal prática denominavam de "rádio interativo". Em geral, o projeto era muito bem gerenciado, em parte porque a ampla assistência fornecida pela USAID tornou possível que uma equipe cuidadosamente selecionada, incluindo supervisores americanos, trabalhasse independentemente da estrutura burocrática normal do Ministério da Educação.

A avaliação do projeto nicaragüense no segundo ano, quando estava funcionando totalmente, mostrou que os estudantes no programa tiveram uma média de $65,6 \%$ de acertos em testes, comparados com apenas os $40,6 \%$ dos grupos que não seguiam o programa. O projeto demonstrou que o ensino suplementar pelo rádio poderia melhorar consideravelmente $o$ aprendizado em uma dada matéria. Como foi mencionado acima, suas lições estão agora sendo aplicadas numa grande gama de projetos em outros países.

\section{A transmissão como parte da reforma educacional}

Como nota Bates, Schramm argumentava que a mídia pode representar um importante papel nas reformas educacionais de países em desenvolvimento, nos quais há carência de professores, falta de recursos para construção, os equipamentos são limitados e muitas crianças estão aproveitando apenas o mínimo do ensino primário. $\mathrm{O}$ ensino é geralmente autoritário e decorado, principalmente porque os professores são mal preparados e é difícil tentar algo original com classes de 40 a 60 crianças. 
Um outro projeto de Stanford ajudou a introduzir aulas pela TV em El Salvador, como parte de uma ambiciosa reforma educacional. O projeto apresentava quatro aulas por semana de espanhol, estudos sociais, ciências, matemática e inglês, para a sétima, oitava e nona séries. Nas avaliações, aqueles que tiveram aulas pela TV educativa obtiveram $15 \%$ a $25 \%$ de acertos a mais nos testes de conhecimentos gerais do que seus colegas que não usavam a TV. Apesar de as transmissões melhorarem os resultados dos testes, a verba, embora alta para os padrões salvadorenhos, não permitiu o uso de recursos mais sofisticados na elaboração da programação, tornando-a menos criativa. $\mathrm{O}$ interesse entre professores e estudantes gradualmente declinou e foi difícil fazer com que o ensino pela TV fosse aceito como uma parte permanente, central do sistema educacional, conforme fora planejado.

Jamison e McAnany resumem sua pesquisa sobre rádio educativo na escola com a conclusão de que, quando as aulas transmitidas dão instrução direta e carregam a principal porção da responsabilidade educacional em uma ou duas matérias, além de aulas centrais cuidadosamente planejadas, melhora-se definitivamente a qualidade do aprendizado, se comparado com a eficácia do professor médio da maioria dos sistemas escolares. Os casos que Jamison e McAnany usam são, na maioria, de países em desenvolvimento onde a formação de professores é frequientemente muito inadequada. Se as aulas transmitidas são usadas para o enriquecimento dos conteúdos e dependem da habilidade de cada professor em planejar sua integração no currículo, as transmissões podem melhorar a qualidade se as condições, como Bates ressalta, forem adequadas.

Talvez o mais convincente seja o fato de que onde a transmissão de aulas é disponível, uma porcentagem muito significativa de escolas e professores fazem uso dela, atribuindo-lhe um peso razoável, durante um longo período.

\section{No treinamento de professores}

Intrínseco a qualquer processo de reforma educacional está um esforço de melhorar o treinamento de professores. A transmissão educacional provou ser especialmente valiosa na ajuda a esse esforço.

Quando a Universidade Aberta começou na Inglaterra, no início dos anos 70, o maior grupo profissional a tirar vantagem do novo serviço e que obteve os melhores recordes subseqüentes de finalização de cursos foi de professores, os quais queriam atualizar seus conhecimentos e melhorar suas possibilidades na carreira, sem deixar seus empregos. Em outras universidades o treinamento de professores tem sido um programa prioritário que tem atraído muitos deles.

Nos países em desenvolvimento, a rápida expansão dos sistemas de escolas primárias significou a contratação de professores que têm apenas um mínimo de educação básica.

No Quênia, Botswana, Swazilândia, Tanzânia e Uganda, programas treinando uma grande quantidade de professores do primeiro grau, através do treinamento a distância, resultou numa impressionante melhoria na performance destes profissionais.

O método de repetição-memorização no qual a criança canta um coro sem fim, devese geralmente ao fato de que o professor não sabe muito sobre o material para poder ensinar de outra forma. No Quênia e na Tanzânia, programas de rádio foram um componente central junto com outros métodos correspondentes. Em ambos os casos, a transmissão regular de rádio foi citada como tendo feito muito no intuito de propiciar uma motivação mais pessoal aos estudantes, ajudar os estudantes mais vagarosos e acompanhar o ritmo dos estudantes no aprendizado das lições. 
Gary Coldevin (DCR, p.5-7, 15) diz que o crescimento da população e a falta contínua de recursos levaram as autoridades em educação do Terceiro Mundo a ver o ensino a distância como sua única esperança viável de atender a demanda por professores razoavelmente atualizados. Distante da possibilidade de oferecer ensino superior convencional para o grande número de professores necessários, o ensino a distância dirigido a professores menos qualificados, recrutados na localidade, tem certas vantagens sobre o método tradicional, pois a formação se dá enquanto eles continuam a ensinar. Os professores podem se aperfeiçoar profissionalmente sem interromper seus ganhos $\mathrm{e}$ sem negligenciar seu trabalho. É o caso de muitos professores rurais em áreas em desenvolvimento que assim fazem para sobreviver. Quando um professor sai de sua esco- la para se aperfeiçoar em uma faculdade, cria-se a necessidade de substitutos, que muito provavelmente serão até menos qualificados. É menos provável que um professor treinado na sua própria região migre para a cidade grande do que aquele que provou as atrações da vida na cidade enquanto estudava na faculdade ou na universidade. Finalmente, mais professores podem ser treinados, gastando-se o equivalente a um quarto ou metade do custo da instrução no campus.

As limitadas conclusões científicas existentes sugerem que os professores treinados a distância possuem performance tão boa quanto os treinados convencionalmente, mas muitos problemas e questões permanecem. Apenas estudos longitudinais da performance de ambos, professores e alunos, podem avaliar adequadamente os resultados a longo prazo. 